\title{
ЭКСПОРТНЫЕ ВОЗМОЖНОСТИ РОССИЙСКИХ ВУЗОВ В СВЕТЕ РЕАЛИЗАЦИИ НАЦИОНАЛЬНЫХ ПРОЕКТОВ
}

\author{
(c) 2019 Платонова Елена Дмитриевна \\ доктор экономических наук, профессор, \\ заведующий кафедрой Экономической теории и менеджмента \\ Московский педагогический государственный университет, Россия, Москва \\ E:mail: ed.platonova@mpgu.edu \\ (c) 2019 Мусарский Марк Михайлович \\ доктор экономических наук, \\ профессор кафедры Экономической теории и менеджмента, директор ИСГО \\ Московский педагогический государственный университет, Россия, Москва \\ E: mail: etm@mpgu.edu \\ (c) 2019 Чжан Тяньхуэй \\ аспирантка кафедры Экономической теории и менеджмента \\ Московский педагогический государственный университет, Россия, Москва \\ E: mail: chzhu95@bk.ru
}

Авторы анализируют основные положения национального, федеральных и приоритетных проектов в сфере экспорта российского высшего образования. На этом основании делается вывод о том, что в данных проектах практически отсутствуют экономическая заинтересованность и экономические стимулы коллективов большинства российских вузов к реализации положений данных проектов.

Ключевые слова: образование, национальный проект, федеральный проект, приоритетный проект, экспорт образования, вузы, рынок образовательных услуг.

В теоретическом и практическом аспектах в новой экономике на первый план выходят вопросы, связанные с формированием человеческого потенциала как на уровне национальногосударственных систем, так и мировой экономики в целом. Это обусловлено многими факторами, в том числе, необходимостью поддержания глобальной конкурентоспособности национальных экономик в условиях, когда индекс развития человеческого потенциала выступает одним из главных индикаторов развитости современных государств. Вместе с тем, исключительная важность международного сотрудничества в развитии сферы образования подчеркнута в программных документах ООН. В частности, в глобальной концепции всемирного движения за образование для всех на первый план поставлена необходимость «единой обновленной повестки дня в области образования, которая была бы всесторонней, масштабной, стимулирующей и охватывающей всех без исключения» [1], [3].

Государственные программы, национальные, приоритетные и федеральные проекты развития всех сфер, в которых происходит воспроизводство человеческих ресурсов и их развитие (здравоохранение, образование, культура, наука, спорт и др.) выступают стратегическими инструментами повышения конкурентоспособности российской экономики, придания ей позитивной динамики и достижения темпов экономического роста выше мировых к 2024 году [12]. Не отрицая важность участия всех перечисленных сфер в формировании человеческого потенциала, особо укажем на роль высшего образования, которое является не только социокультурным феноменом, позволяющим сохранять и преумножать культурно-исторические народов России, но и геополитическим инструментом «мягкой силы», позволяющим решать текущие и перспективные задачи продвижения «русского мира».

Обеспечение глобальной конкурентоспособности российского образования выступает одной из стратегических целей масштабного национального проекта «Образование» (2019-2024), утвержденного в декабре 2018 г. 
[4]. Амбициозной задачей, поставленной перед отечественным образованием в федеральном проекте «Экспорт образования», как составной части данного национального проекта, является наращивание экспортного потенциала российского образования и «увеличение не менее чем в два раза количества иностранных граждан, обучающихся в образовательных организациях высшего образования и научных организациях» [5].

Данная задача была конкретизирована в Паспорте федерального проекта «Экспорт образования» (далее - Проект-2018): увеличение численности иностранных граждан, обучающихся в организациях, осуществляющих образовательную деятельность по программам высшего образования с 241 тыс. чел. в 2019 г. до 425 тыс. чел. к 2024 г. при базовом значении 201 тыс. чел. (2017 г.) [5].

До утверждения и начала реализации Проекта-2018 в приоритетном проекте «Развитие экспортного потенциала российской системы образования» (далее - Проект-2017), утвержденного в мае 2017 г., зафиксирована цель: «Увеличение доли несырьевого экспорта Российской Федерации за счет повышения привлекательности российского образования на международном образовательном рынке» [6]. Согласно планируемым показателям за период реализации данного проекта с мая 2017 г. по ноябрь 2025 г. численность контингента иностранных учащихся дневных факультетов российских вузов, обучающихся на территории Российской Федерации (без учета совместных университетов за пределами Российской Федерации, филиалов и др. зарубежных подразделений российских вузов), должна возрасти с 220 тыс. чел. в 2017 г. до 710 тыс. чел. в 2025 г., а в 2024 г. составить 600 тыс. чел. при базовом значении 200 тыс. чел (2016 г.). Как видно из данных, показатели приоритетного Проекта-2017 более амбициозны, чем заявленные в федеральном Проекте-2018, на что обращают внимание исследователи [17].

Расширение экспорта образовательных услуг в сфере высшего образования - глобальный тренд в развитии современной экономики на протяжении всего 21 века, что отражает одно направленность действия многих факторов. Не претендуя на полноту их освещения, выделим, среди них, кроме потребности новой экономики в высококвалифицированных специалистах, во-первых, развитие информационных тех- нологий и новых технологий предоставления образовательных услуг (дистанционные технологии, он-лайн обучение); во-вторых, быстрый экономический рост в странах со значительным населением (Китай, Индия, страны с развивающимися рынками) и наличия неудовлетворенного спроса на высококачественные образовательные услуги в области новых технологий и бизнес-образования; в-третьих, предъявление транснациональным капиталом повышенного спроса на сотрудников, получивших высшее образование в развитых странах и владеющих иностранным (английским) языком; в-четвертых, миграционные настроения молодежи побуждают к получению университетского образования в странах с более высоким уровнем жизни с перспективой получения высокооплачиваемого рабочего места; в-пятых, развитие системы кредитования на достаточно выгодных для домохозяйств условиях. Безусловно, определенную роль сыграли универсализация двухуровневого высшего образования (бакалавр, магистр) в мировом образовательном пространстве, студенческая мобильность, присоединение стран к положениям, которые наиболее полно отражены в Болонской конвенции [16].

В настоящее время мировой рынок образовательных услуг является наиболее быстро растущим социальным сегментом рынка услуг после рынка здравоохранения. При этом, по данным правительственных экспертов, рынки дистанционного электронного обучения и обучения иностранным языкам покажут среднегодовой прирост на уровне не менее 20 процентов [11].

На протяжении долгого периода бесспорными лидерами на рынке высшего образования являются вузы США. В 2018/2019 учебном году численность студентов, получающих академическую степень в американских колледжах и университетах, составляла 872,2 тыс. чел. При этом на бакалавриате обучалось 431,9 тыс. чел., в магистратуре - 220,6 тыс. чел., в аспирантуре 132,6 тыс. чел. [13]. Наиболее многочисленная когорта студентов обучается в New York University (19,6 тыс. чел.), University of Southern California (16,3 тыс.чел.), Northeastern University - Boston (16,1 тыс. чел.) [14].

Десятый год подряд студенты из Китая представляют самую большую группу иностранных студентов в США: в 2018/2019 году по программам бакалавриата, магистратуры и других форм 
обучалось 369,5 тыс. студентов. Второй по численности студентов в США является Индия (202,0 тыс. чел.), а затем с большим отрывом Южная Корея (52,3 тыс. чел.) и Саудовская Аравия (37,1 тыс. чел.). Экспорт образовательных услуг составляет по объему весомую часть национального рынка услуг США. По данным Министерства торговли США в 2018 году иностранные студенты внесли в экономику США 44,7 млрд. дол., что на 5,5\% больше, чем в 2017 году [15].

Реализованный экспортный потенциал российских вузов значительно скромнее: в 2018/2019 учебном году в них обучалось по программам бакалавриата, специалитета, магистратуры 247,7 тыс. иностранных студентов. Основными потребителями образовательных услуг являлись студенты из стран СНГ, Балтии, Абхазии и Южной Осетии - на их долю приходилось около 75\%. В целом наблюдается положительная динамика - по сравнению с 2000/2001 учебным годом численность иностранных студентов увеличилась в 4,2 раза [10, с. 143]. Однако текущая ситуация, не отражающая реальные экспортные возможности российского высшего образования, является результатом негативных явлений, корни которых уходят в трансформационный период отечественной экономики [7]. Вместе с тем, российские вузы, несмотря на имевшее место недофинансирование, физический износ основных фондов и старение научно-педагогических кадров, сохранили весомый интеллектуальный потенциал, необходимый для расширения экспорта образовательных услуг в жестко конкурентной бизнес-среде глобального рынка образования.

В целях расширения экспортных возможностей российских вузов в паспорте федерального Проекта-2018 намечены конкретные мероприятия, осуществление которых позволит, по мнению авторов проекта, достичь к 2024 году целевого показателя по численности иностранных студентов, обучающихся по программам российских вузов. Это, прежде всего, использование уже созданных за рубежом инфраструктурных ресурсов (Славянские университеты, филиалы российских вузов) и создание новых ресурсных центров. Во-вторых, проведение маркетинговых кампаний с учетом специфики страновых рынков образовательных услуг и выбора 10 ведущих мировых СМИ для продвижения информации о российском образовании, проводимых олимпиадах и конкурсах, по ито- гам которых иностранные граждане могут быть зачислены в рамках квоты Правительства РФ (не менее 20\% иностранных граждан от их общего числа). В-третьих, создание современных многофункциональных студенческих городков для проживания иностранных и иногородних студентов, а также ввод за счет всех источников финансирования 77 тыс. мест в построенных, отремонтированных и реконструированных общежитиях. В-четвертых, внесение изменений в нормативные правовые акты (совершенствование визовых процедур; информационная открытость Интернет-ресурсов и создание 50 Интернет-сайтов на иностранных языках). В-пятых, трудоустройство не менее $5 \%$ иностранных выпускников по дефицитным специальностям в российских компаниях, в том числе, за рубежом. В-шестых, 60 российских университетов должны иметь международные аккредитованные программы, а 5\% преподавателей вести предметы на иностранном языке.

Вышеперечисленные мероприятия Проекта-2018 по расширению экспорта высшего образования должны рассматриваться в совокупности с другим федеральным проектом - «Молодые профессионалы (Повышение конкурентоспособности профессионального образования)» национального проекта «Образование» - в части мероприятий раздела «Глобальная конкурентоспособность высшего образования». Кроме того, прослеживается взаимосвязь федерального Проекта-2018 с приоритетными проектами «Вузы как центры пространства создания инноваций» (2016-2025 гг.) и «Современная цифровая образовательная среда» (2016-2025 гг.). В первом проекте определяется цель - «обеспечить устойчивую глобальную конкурентоспособность в 2025 году не менее 10 ведущих российских университетов» [8]. Целью второго проекта является развитие «российского цифрового образовательного пространства и увеличения числа обучающихся образовательных организаций, освоивших онлайн-курсы до 11 млн. человек к концу 2025 года» [9].

В разделе «Глобальная конкурентоспособность высшего образования» детально прописаны требования к вузам, выполнение которых обеспечит государственную поддержку мероприятий по обретению вузом «глобальной конкурентоспособности». Среди основных требований к вузам, получившим государственную поддержку, выступают требования по до- 
стижению многих показателей, среди которых вхождение не менее двух лет подряд в топ-1000 глобальных институциональных рейтингов (QS, THE, ARWU), а также вхождение не менее двух лет подряд в топ-200 как минимум одного предметного или отраслевого глобального рейтинга. При этом поставлена комплексная задача обеспечить 10 место России в мире по присутствию университетов в ТОП-500 глобальных рейтингов университетов (QS, THE, ARWU) к 2024 году.

Принципиальные положения Проекта-2017 во многом повторяют содержание Проекта-2018 в части нормативно-правового обеспечения экспорта образовательных услуг, снятия административных барьеров, информационномаркетинговой деятельности по продвижению «бренда» российского образования, а также укрепления материально-технической базы образовательных учреждений (строительство и модернизация учебных корпусов, общежитий и др.). Вместе с тем, в Проекте-2017 большое внимание уделяется созданию институтов и механизмов реализации данного проекта. К их числу следует отнести, дорожную карту по совершенствованию российской нормативно-правовой базы; центр компетенций по подготовке, переподготовке и повышению квалификации сотрудников международных служб российских образовательных организаций; консорциум опорных университетов; межведомственную рабочую группу, а также механизм привлечения наиболее талантливых иностранных граждан; языковую платформу информационной системы Russian.study; индекс экспортной активности российского вуза. Кроме того, в рассматриваемом проекте предусматривается разработка ряда программ, в том числе, программы «Благоприятная среда для иностранных учащихся»; программы трансграничного образования (франчайзинг, валидация и др.); программы «Послы Российского Образования»; программы вывода в международное образовательное пространство десяти образовательных программ в дистанционном формате на иностранных языках; программы продвижения русского языка за рубежом.

Источником финансового обеспечения рассматриваемых проектов выступают средства федерального бюджета: в реализацию мероприятий Проекта-2018 в период с 2019 по 2024 гг. запланировано вложить 107493,29 млн. руб., в Проект-2017-4972,1 млн. руб. с 2018 по 2025 гг. (цифра прогнозная) [5], [6].

Оценивая результаты анализа содержания федерального Проекта-2018 и приоритетного Проекта-2017, а также других федеральных и приоритетных проектов с точки зрения расширения экспортных возможностей российского высшего образования, можно сделать несколько выводов. Прежде всего, неясен механизм их согласования в процессе одновременной реализации. Существенное различие в объемах финансирования и запланированной численности привлеченных иностранных студентов по завершению данных проектов, даже с учетом различных сроков, позволяет предположить, что их авторы по-разному использовали исходные данные и применяли различные методы и приемы прогнозирования. При этом проекты концептуально схожи в том, они представляют собой набор возможно обоснованных мероприятий, но оставляют нерешенными вопросы заинтересованности и стимулов коллективов вуза в их практической реализации. Иными словами, по терминологии известного экономиста Г.Б. Клейнера в проектах не прослеживаются экономические субъекты, как инициирующие выполнение намеченных мероприятий в виду экономической заинтересованности, а не административного принуждения, так и содействующие их реализации (прозелиты, пропагандисты, дистрибьютеры) [2]. В данном случае к таким субъектам неправомерно относить только бюрократические структуры (министерства, ведомства и аппарат управления вузов).

Государственная поддержка экспортной активности российских вузов обусловливается такими требованиями, выполнение которых под силу только крупным ведущим вузам - в основном участникам проекта «5-100», или имеющим статус «федеральный», «национальный исследовательский», «опорный» с дополнительными ресурсными возможностями. Включение в эти требования вхождение вуза в глобальные рейтинги, даже на уровне топ-500 и топ-1000, означает, что российский вуз в лице профессорскопреподавательского состава «вступает» на конкурентное бизнес-поле, на котором глобальные игроки - в основном частные престижные вузы - успешно работают десятилетиями. В виду того, что стоимость одной публикации, которая может быть размещена в международных наукометрических базах (Web of Science, Scopus и др.), зачастую превышает среднемесячную 
оплату труда преподавателей в региональных вузах, им становится экономически не выгодна публикационная активность в изданиях, индексируемых международными агенствами. В этих обстоятельствах необходимо авансирование значительных вложений в конкурентную борьбу с международными бизнес-структурами (зарубежными университетами и колледжами) за долю мирового рынка образовательных услуг, а также обоснование экономической эффектив- ности данных проектов.

Таким образом, экспортные возможности российских вузов напрямую зависят не только от наличия добротно выполненных проектов, но в большей мере - от экономической заинтересованности всех агентов, оперирующих в российском образовательном пространстве, в расширении сферы (сегмента) предоставления образовательных услуг иностранным студентам.

\section{Библиографический список}

1. Инчхонская декларация и ЦУР 4 - Образование 2030: Рамочная программа действий. Инчхон, Республика Корея. 2015.. URL: unesdoc. unesco.org/images/0024/002456/245656R.pdf (дата обращения 15.11.2019).

2. Клейнер Г.Б. Институциональные изменения: селекция, проектирование или протезирование? URL: kleiner.ru/pubs/institutsionalnyie-izmeneniya-selektsiya-proektirovanie-ili-protezirovanie/(дата обращения 10.12.2019)

3. Платонова Е.Д., Мусарский М.М. Всемирное движение за образование для всех как фактор развития мировой экономики// Экономический журнал, 2018. 3 (51) С. 108-120.

4. Паспорт национального проекта «Образование». Утвержден президиумом Совета при Президенте Российской Федерации по стратегическому развитию и национальным проектам (протокол от 24 декабря 2018 г. № 16) URL: http://government.ru/info/35566 (дата обращения 15.12.2019).

5. Паспорт федерального проекта «Экспорт образования». URL: http:/майскийуказ.pф/upload/iblock/21f/ Eksport-obrazovaniya-_obnov.-red_.pdf (дата обращения 05.12.2019).

6. Паспорт приоритетного проекта «Развитие экспортного потенциала российской системы образования». Утвержден президиумом Совета при Президенте Российской Федерации по стратегическому развитию и приоритетным проектам (протокол от 30 мая 2017 г. № 6) URL: http://d-russia.ru/wp-content/uploads/2017/06/ education_export.pdf (дата обращения 05.12.2019).

7. Платонова Е.Д. Современная теория и практика накопления (трансформационный аспект) / Под ред.д.э.н., проф. Е.В. Юферевой. М.: Изд-во АПКиППРО, 2006.- 367 с.

8. Паспорт приоритетного проекта «Вузы как центры пространства создания инноваций». Утвержден президиумом Совета при Президенте Российской Федерации по стратегическому развитию и приоритетным проектам (протокол от 25 октября 2016 г. № 9) URL: http://static.government.ru/media/files/OnTUmegFLNj5U qtac57y1WG1EtMG9ABe.pdf (дата обращения 05.12.2019).

9. Паспорт приоритетного проекта «Современная цифровая образовательная среда в Российской Федерации». Утвержден президиумом Совета при Президенте Российской Федерации по стратегическому развитию и приоритетным проектам (протокол от 25 октября 2016 г. № 9) URL: static.government.ru/media/files/8 SiLmMBgjAN89vZbUUtmuF5lZYfTvOAG.pdf (дата обращения 05.12.2019).

10. Россия в цифрах. 2019: Крат.стат.сб./Росстат- М., 2019-549 с.

11. Стратегия развития экспорта услуг до 2025 года. Утверждена распоряжением Правительства Российской Федерации от 14 августа 2019 г. № 1797-p URL: static.government.ru/media/files/S125RuCTUAiCH5V7RlHUhC AcOTndx9PJ.pdf (дата обращения 15.12.2019).

12. Указ Президента РФ от 07.05.2018 № 204 (ред. от 19.07.2018) «О национальных целях и стратегических задачах развития Российской Федерации на период до 2024 года». URL: http://www.kremlin.ru/acts/bank/ 43027 (дата обращения 15.12.2019).

13. Data on academic level for international students studying in the United States.URL: https://www.iie.org/ Research-and-Insights/Open-Doors/Data/International-Students/Academic-Level (дата обращения 05.12.2019).

14. Data on the leading host institutions. URL: https://www.iie.org/Research-and-Insights/Open-Doors/Data/ International-Students/Leading-Host-Institutions (дата обращения 15.12.2019).

15. Number ofInternationalStudentsintheUnited States.URL:https://www.iie.org/Why-IIE/Announcements/2019/11/ Number-of-International-Students-in-the-United-States-Hits-All-Time-High (дата обращения 15.12.2019). 
16. Platonova E., Bogomolova J. The revealed tendencies of the global transformation in the Labour market in modern economy. Abstract. 8th annual International Conference of Education, Research and Innovation (Sevilla, Spain, 1618 November, 2015)/ ICERI2015 Proceedings, page 4759. URL: http://ibrary.iated.org/view/PLATONOVA2015REV (дата обращения 15.12.2019).

17. Fedotova Olga, Platonova Elena, Tregubenko Elena, Avanesyan Grant. Development of the export potential of Russian education in the modern strategic discourse/ SHS Web Conf. Volume 70, 2019 «Trends in the Development of Psycho-Pedagogical Education in the Conditions of Transitional Society» (ICTDPP-2019).Article Number 02005. URL: https://www.shs-conferences.org/articles/shsconf/abs/2019/11/contents/contents.html (дата обращения 15.12.2019). 